\title{
The Patient Safety and Quality ImProvement ACT OF 2005: AN INVITATION FOR SHAM PEER REVIEW IN THE Health Care Setting
}

\author{
Leigh Ann Lauth*
}

TABLE OF CONTENTS

I. INTRODUCTION

II. REDUCTION OF MEDICAL ERRORS AS THE PRIMARY

MOTIVATION BEHIND THE PSQIA OPERATIONS-

BASED MEDICAL ERRORS AND ADVERSE EVENTS

IN HOSPITALS

A. Operations-Based Medical Errors and Adverse

Events in Hospitals

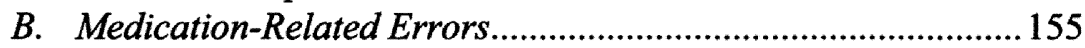

III. THE PATIENT SAFETY AND QUALITY IMPROVEMENT

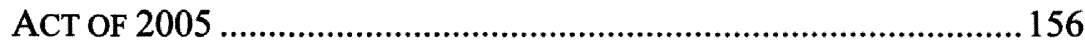

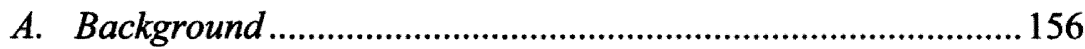

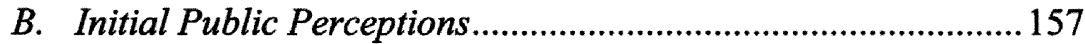

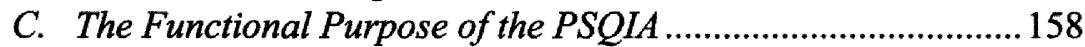

D. Congressional Debates Concerning the PSQIA .........................158

E. The Main "Players" of the PSQIA …………..............................160

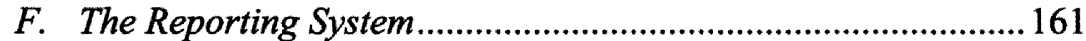

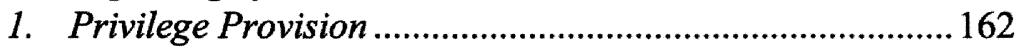

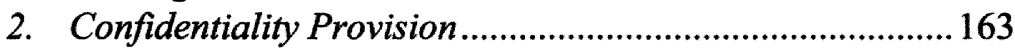

IV. WILL THE PATIENT SAFETY AND QUALITY

IMPROVEMENT ACT OF 2005 ACHIEVE THE

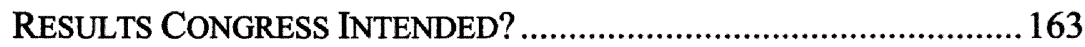

A. Anticipated Underutilization of PSOs by Providers .................... 164

B. Likely Development of Bad Faith or Sham Peer Review........... 166

1. A Look at State Peer Review Protection Statutes

That Have Been Used in Good Faith ..................................166

2. Sham Uses of Peer Review Statutes and Policies ...............167

a. The Semmelweis Society and protecting

physicians from sham peer review

V. CONCLUSION

* J.D., 2006, Indiana University School of Law, Indianapolis, Indiana; B.A., 2003, DePauw University, Greencastle, Indiana. Thanks to Professor Eleanor Kinney for her direction and insight on this important topic and Kevin R. O'Neill for challenging my arguments and provoking me to cogitate about them more carefully. 


\section{INTRODUCTION}

Out of the many noteworthy epidemics facing the health care world today, two of specific relevance to patient safety and quality improvement emerge: medical error and sham peer review. When Congress passed the Patient Safety and Quality Improvement Act of 2005 ("PSQIA") its main intention was to reduce the number of deaths due to medical error that occur in the United States annually. ${ }^{1}$ Unfortunately, in pursuit of this goal, Congress created the framework for an unintended side-effect, malevolent or sham peer review.

Part II of this Note discusses the Institute of Medicine's ("IOM") report, To Err is Human: Building a Safer Health System, which serves as the basis for the PSQIA. ${ }^{2}$ Critically, this report uncovers that as many as 98,000 people die each year in America due to medical errors. ${ }^{3}$ These errors vary from preventable adverse events, such as operations performed on the wrong body part, to medications administered in poisonous doses. Based on these and similar findings, the IOM recommended in its report that a national voluntary reporting system be developed as a forum of analysis to which health care providers can report their medical errors. ${ }^{4}$

Part III of this Note describes the PSQIA itself. ${ }^{5}$ The purpose of the PSQIA is to reduce the number of medical errors ${ }^{6}$ through voluntary reporting by physicians and other health care providers to Patient Safety Organizations ("PSOs"). ${ }^{7}$ Once the error has been submitted to the PSO, the information contained in the report will gain, to an extent, an evidentiary privilege, ${ }^{8}$ as well as confidential status. ${ }^{9}$ Congress intended that both the privilege and confidentiality provisions would serve as an incentive for health care providers to report the medical errors they commit or witness. ${ }^{10}$

Part IV of this Note assesses the PSQIA's likelihood of success in reducing medical errors through the voluntary reporting system. In addition, it also examines whether or not health care providers will actually utilize the voluntary reporting mechanism created by the PSQIA. Statistics published by The Joint Commission regarding that entity's sentinel event policy shed light on the ex-

1 See generally Patient Safety and Quality Improvement Act of 2005, Pub. L. No. 109$41, \S \S 921-26,119$ Stat. 424 (2005) (codified as amended in scattered sections of 42 U.S.C.).

2 COMm. on Qualtity of Health Care In AM., InST. OF MED., To ERr Is Human: BUILDING A SAFER HEALth SYSTEM (Linda T. Kohn, Janet M. Corrigan \& Molla S. Donaldson eds., 2000) [hereinafter To ERR Is HUMAN]. See also H.R. REP. No. 109-197, at 9 (2005).

3 To ERR Is HUMAN, supra note 2, at 26.

4 Id. at 6.

5 Patient Safety and Quality Improvement Act \$§ 921-26.

6 See H.R. REP. No. 109-197, at 9 (submitted by Mr. Barton of Texas).

7 Patient Safety and Quality Improvement Act $\S \S$ 921(4), 923.

8 Id. § 922(a).

9 Id. § 922(b).

10151 CONG. REC. S8741, S8741 (2000). 
tent to which health care providers will utilize the new reporting system. ${ }^{11}$ The current use of peer review committees in health care settings, which is becoming increasingly malevolent among providers, is also explored. ${ }^{12}$ This Part also considers the possibility that the PSQIA could have an effect exactly opposite of what Congress intended.

This Note concludes by setting forth the proposition that the PSQIA, much like the Health Care Quality Improvement Act of 1986 ("HCQIA"), 13 will cause a surge in what is called "sham peer review."14 This result, unfortunately, is in stark contrast to the legislative purposes and intent underlying the PSQIA.

\section{REDUCTION OF MEDICAL ERRORS AS THE PRIMARY MOTIVATION BEHIND THE PSQIA}

In 1999, the IOM issued its report, To Err is Human: Building a Safer Health System. ${ }^{15}$ The report was the result of data gathered from two major studies, the Harvard Medical Practice Study and the Colorado-Utah Study. ${ }^{16}$ Each study focused on the rate that medical errors occur in the United States, while also incorporating the recommendations from IOM's Quality of Health Care in America Committee. ${ }^{17}$ The Harvard Medical Practice Study was composed by randomly selecting more than 30,000 persons who had been discharged from fifty-one randomly selected hospitals in the state of New York. ${ }^{18}$ Similarly, but on a smaller scale, the Colorado-Utah study looked at a random sample of medical records of 15,000 patient discharges, which were compiled from a sample representing two state hospitals. ${ }^{19}$

The collective data of these two studies demonstrated the frightening rate at which medical errors have recently occurred in the United States. "When

11 THE JOINT COMM'N, SENTINEL EVENT (2006), http://www.jointcommission.org/NR /rdonlyres/690008C7-EAB2-4275-BC7B-68B37481D658/0/SE_Chap_Sept06.pdf.

${ }_{12}$ Gail Garfinkel Weiss, Is Peer Review Worth Saving?, MED. EcoN., Feb. 18, 2005, at 46,47 (2005).

13 Health Care Quality Improvement Act of 1986, Pub. L. No. 99-660, 100 Stat. 3784 (codified as amended in scattered sections of 42 U.S.C.).

14 Weiss, supra note 12 (referring to the Semmelweis Society). See generally Semmelweis Soc'y Int'l, Medical Peer Review with Clean Hands, www.semmelweis.org (last visited Jan. 8, 2007) (The Semmelweis Society is an organization that helps physician-victims of sham peer review). See also infra Part IV.B.2 (discussing the Semmelweis Society in further detail).

15 To ERR Is HUMAN, supra note 2.

16 Id. at 26.

17 Id. at 5 ("[The IOM committee] was formed in 1998 to develop a strategy that will result in a threshold improvement in [the] quality [of health care in America]. .."). The IOM report delivered significant data gathered from a 1984 New York study and a 1992 study from Colorado and Utah. Id. at 26.

18 Id. at 30.

19 Id. 
extrapolated to the over 33.6 million admissions to U.S. hospitals in 1997, the results of these two studies imply that at least 44,000 and perhaps as many as 98,000 Americans die each year as a result of medical errors." 20 Even more staggering is that the number of deaths in the United States due to medical errors is greater than the number of deaths attributable to motor vehicle accidents $(43,458)$, breast cancer $(42,297)$, or AIDS $(16,516){ }^{21}$ When analyzing a piece of legislation that aims to correct, or at least minimize, the problem of medical errors, it is important to maintain a real-life frame of reference with regard to what particularly motivated the lawmakers. Of particular interest are the errors that arise from mistakes made in the everyday operation of a hospital, as well as mistakes related specifically to prescription medications.

\section{A. Operations-Based Medical Errors and Adverse Events in Hospitals}

Adverse events and operations-based errors in hospitals can lead to startling results, especially when in hindsight it becomes more clear how easily the error could have been avoided. Although not all adverse events stories have tragic endings, the events themselves are still causes for concern. Perhaps it is the failed treatment routines and standard operating procedures practiced by hospitals that the health care industry should learn from when reflecting on adverse events.

Consider, for example, the real-life story of a fourteen-year-old boy who arrives at the emergency department of a rural hospital. ${ }^{22}$ He presents with symptoms consistent with an overdose of an antidepressant, including a highly irregular heart rate that is threatening to cease at any moment. ${ }^{23}$ The physicians need to get the patient to the pediatric intensive care unit of the nearest regional hospital immediately, but it is ten miles away. ${ }^{24}$ The attending physician orders an ambulance but does not specify the ambulance type. ${ }^{25}$ The ambulance arrives and the trip begins through rush hour traffic. ${ }^{26}$ Soon the physician recognizes the need to hook the patient up to a heart monitor to detect deteriorating function in order to respond with medication or a defibrillator to shock the patient's heart back into its intended rhythm should such a need arise. ${ }^{27}$ The physician looks around the ambulance only to realize that there is no heart monitor

${ }^{20} I d$. at 26.

21 Id.

22 ROBERT M. WACHTER \& KAVEH G. SHOJANIA, INTERNAL BlEEDING: THE TRUTH BEHIND AMERICA's TERRIFYING EPIDEMIC OF MEDICAL MISTAKES 14-17 (2004) (describing a medicalmistake event that took place in the mid-1980s).

${ }^{23}$ Id. at 14.

24 Id. at $14-15$.

25 Id. at $15-16$.

${ }^{26} \mathrm{Id}$.

27 Id. at 15. 
and no defibrillator; the physician failed to order a "Priority One Ambulance."28 The physician assumed that the other hospital personnel responsible for ordering the ambulance would have known which type of ambulance to request based on the facts provided concerning the patient's condition, ${ }^{29}$ but the nurses and other staff in the emergency department failed to make this assessment. ${ }^{30}$

From this story, it is easy to conceive of how such an error can occur based on a simple miscommunication, or complete lack of communication. Not a single person in this story acted in a manner that was affirmatively adverse to the patient, yet the patient's safety was still compromised.

Consider also the mistaken identity real-life story of Joan Morris and Jane Morrison. ${ }^{31}$ Joan Morris was recovering from embolization, a procedure that was intended to relieve her of a brain aneurysm. ${ }^{32}$ Jane Morrison was lying in bed, getting ready to have her cardiac electrophysiology study, which was going to eliminate the parts of her heart that were causing it to beat dangerously irregularly. ${ }^{33}$ Meanwhile, Joan Morris was scheduled to be discharged that morning to go home, recover, and prepare for her next embolization procedure. ${ }^{34}$ Instead, the hospital system, which often identifies patients by his or her last name, placed Joan Morris in the electrophysiology study lab while Jane Morrison remained lying in her hospital bed with her heart continuing to function irregularly. ${ }^{35}$ Due to the error caused by the surname mix-up, Joan Morris received a cardiac procedure that she did not need, and Jane Morrison missed the very same procedure that she did need to correct her irregularly beating heart. ${ }^{36}$ Again, here is an example of a medical error caused by miscommunication, but this time the error is one that stemmed from a cursorily-formed patient-identifying hospital operating procedure.

\section{B. Medication-Related Errors}

Medication-related errors, which affect a substantial number of people and are responsible for large increases in health care costs, are one of the most common types of errors. ${ }^{37}$ For example, in a study of 101,022 medication orders from two hospitals for children, 479 fallible medication orders were un-

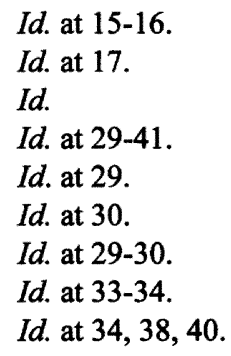

E.g., To ERR Is HUMAN, supra note 2, at 28. The Harvard Medical Practice Study found that drug complications were the most common type of adverse event, occurring nineteen percent of the time. Id. at 30 . 
covered and twenty-seven of them were potentially lethal errors. ${ }^{38}$ The occurrence rate of this type of error has increased over the years. ${ }^{39}$

In a review of U.S. death certificates between 1983 and 1993, it was found that 7,391 people died in 1993 from medication errors (accidental poisoning by drugs, medicaments, and biologicals that resulted from acknowledged errors by patients or medical personnel), compared with 2,876 people in 1983 , representing a 2.57 -fold increase. ${ }^{40}$

These statistics demonstrate the severity of the consequences stemming from medication-related errors and colorfully illustrate the rising trend in their occurrence.

Congress repeatedly cited reports regarding the rate of medical errors that occur in the United States, such as those discussed above, viewing them as the driving force behind the PSQIA. ${ }^{41}$ It seems that Congress's general thought process with the PSQIA was as follows: If the fear of malpractice litigation, which is so frequently harbored by health care providers, can be curbed by new reporting protection laws, providers will be more inclined to report adverse medical errors to data collection organizations. Such organizations will then analyze, review, and provide feedback concerning the reported medical errors, and eventually the rates of death due to medical mistakes will be lowered. Hence, the birth of the PSQIA. ${ }^{42}$

\section{THE PATIENT SAFETY AND QUALITY IMPROVEMENT ACT OF 2005}

\section{A. Background}

The Patient Safety and Quality Improvement Act of 2005 was signed into law by President George W. Bush on July 29, 2005. ${ }^{43}$ Preliminary versions of what ultimately became the PSQIA, however, had been circulating in Congress for an extended period of time and featured elements that were notably different from the final bill. The first of many congressional hearings on the PSQIA took place in late 1999 and early $2000 .^{44}$ These hearings established the general purpose of the PSQIA, which is to encourage medical error reporting, while pro-

38 Id. at 33 .

39 Id. at 32.

40 Id.

41 Medical Mistakes: Joint Hearings Before the Subcomm. on Labor, Health and Human Services, and Education, and Related Agencies of the S. Comm. on Appropriations, the S. Comm. On Health, Education, Labor, and Pensions, and the S. Comm. on Veterans' Affairs, 106th Cong. 1, 55, 99, (2001) [hereinafter Hearings 1999-2000]. See generally To ERR Is HUMAN, supra note 2.

42 Patient Safety and Errors Reduction Act, S. 2738, 106th Cong. (2000) (enacted).

43 President Signs Patient Safety and Quality Improvement Act of 2005, GLOBAL NEwS WIRE, July 29, 2005, available at www.lexisnexis.com (click on News \& Business; click on Individual Publications; click on Global News Wire; enter title).

${ }^{44}$ Hearings 1999-2000, supra note 41, at 1, 5, 61, 99. 
viding some element of peer review protection. ${ }^{45}$ An array of testimonials were heard during the course of these hearings, including discussions of general types of medical errors, patient experiences with medical errors, and recommendations for policy responses, including the importance of making sure that "health care providers can have an opportunity to provide high-quality health care that they were trained to provide in a safe and an effective environment."

\section{B. Initial Public Perceptions}

The medical industry and others who were interested in reducing the rate of medical errors applauded the signing of the bill into law. ${ }^{47}$ President George $\mathrm{W}$. Bush stated, on the day he signed the bill into law, that the "bill is a critical step toward our goal of ensuring top-quality, patient-driven health care for all Americans."48 The President further described how the PSQIA aimed to reduce medical errors through improving the channels of communication among providers:

The Patient Safety and Quality Improvement Act will help ensure that Americans continue to benefit from the greatest medical system in the world. To maintain the highest standards of care, doctors and nurses must be able to exchange information about problems and solutions. Yet in recent years, many doctors have grown afraid to discuss their practices because they worry that the information they provide will be used against them in a lawsuit. ${ }^{49}$

Other commentary from various news sources, made in immediate reaction to the bill signing, showed enthusiastic support for the PSQIA that may have been somewhat overly optimistic as to the PSQIA's capabilities and function. ${ }^{50}$ One article addressed the PSQIA by stating:

45 H.R. REP. No. 109-197, at 9 (2005).

46 Hearings 1999-2000, supra note 41, at 5.

47 See New Patient Safety Act Shields Those Who Report Medical Errors, 5 FDANEws DRUG DAILY BULLETIN, at 16 (2005), available at www.lexisnexis.com (click on News \& Business; click on Individual Publications; click on FDAnews Drug Daily Bulletin; enter title); Tony Fong, Protection for Reporting: Law Creating Databases Snuffs Fear of Litigation, 35 MODERN HEALTHCARE 12, 12 (2005).

48 President Signs Patient Safety and Quality Improvement Act of 2005, supra note 43 (statement of President George W. Bush).

49 Id.

50 See, e.g., New Patient Safety Act Shields Those Who Report Medical Errors, supra note 47; Fong, supra note 47. 
The Patient Safety and Quality Improvement Act . . . creates a national database for nonidentifiable patientsafety data. The information would be used to develop steps to avoid medical errors. Under the legislation, the confidentiality of information reported to patient-safety organizations approved by [the Department of Health and Human Services] . . . would be guaranteed. The law also shields providers from litigation if they report medical errors as part of the effort to build the database. ${ }^{51}$

While it is true that the PSQIA provides certain protection in the way of both confidentiality and privilege provisions, it does not shield a provider from litigation. $^{52}$ There is nothing in the PSQIA that prevents victims of medical errors from bringing an action against the responsible provider.

\section{The Functional Purpose of the PSQIA}

Testimony taken during congressional hearings on the PSQIA identified the different needs for the PSQIA, ranging from the need to reduce medical errors ${ }^{53}$ to the need to develop information sharing systems. ${ }^{54}$ For example, the final House of Representatives' Report on the PSQIA stated, "[the] bill is intended to encourage the reporting and analysis of medical errors and health care systems by providing peer review protection of information reported to patient safety organizations for the purposes of quality improvement and patient safety." ers some assurance that they are able to discuss their medical errors in an effort to learn from them, and in turn reduce their occurrence without immediately exposing themselves to liability. ${ }^{56}$

\section{Congressional Debates Concerning the PSQIA}

The final reports from the Senate and the House reveal Congress's intent regarding the enactment of the PSQIA. One account from Representative

51 Fong, supra note 47.

52 Patient Safety and Quality Improvement Act of 2005, Pub. L. No. 109-41, § 922, 119 Stat. 424, 427 (codified as amended in scattered sections of 42 U.S.C.).

53 See supra Part II.

54 For example, the Committee on Energy and Commerce pointed out that while "[i]n its 1999 report, To Err is Human, the Institute of Medicine . . . estimated that 44,000 to 98,000 Americans die each year as a result of medical errors; however, providers have little to no incentive to report or analyze errors to improve the quality of health care." H.R. REP. No. 109-197, at 9 (2005).

\footnotetext{
55. $I$.

56 Id.
} 
Brown of Ohio states the following:

The reality is that the consequences of reporting medical errors can be onerous, which deters some who commit or witness medical errors from documenting them.

This legislation is intended to overcome that obstacle. To reduce the number of medical errors, we need to understand what causes them and address those causes. Accurate and complete information on medical errors is the first step. ${ }^{57}$

In a more direct assessment of Congress's intent behind the PSQIA, a House Representative stated that the PSQIA establishes a framework for providers to report their medical errors to patient safety organizations on a voluntary basis. ${ }^{58}$ The PSOs will then "analyze the data and recommend steps providers could take to prevent such errors from occurring in the future."59 Particularly, the work done by the PSOs will be incredibly valuable in "identifying national trends on medical errors and recommending how to prevent them."60 Most importantly, the PSQIA was thought to be a tool which encourages information sharing with regard to medical errors by keeping the information that the health care provider shares with the PSO from being used against him or her. "The bill would preclude this information, termed patient safety work product, from being used against providers in civil and administrative proceedings, disclosed pursuant to Freedom of Information Act requests, or used to carry out adverse personnel actions." $" 61$

It is important to take notice, however, that Congress did not intend for the legislation to serve as a limit to providers' medical malpractice liability. ${ }^{62}$ Specifically, with regard to the privilege and confidentiality provisions of the PSQIA, "it is not the intent of this legislation to establish a legal shield for information that is already currently collected or maintained separate from the new patient safety process, such as a patient's medical record."63 In other words, if information is already available to a patient or a patient's attorney, the

57151 CONG. REC. H6673, H6677 (2005) (statement of Mr. Brown of Ohio).

58 Id. at H6676 (statement of Mr. Bilirakis of Florida) (original sponsor of the legislation).

59 Id. (statement of Mr. Bilirakis of Florida).

${ }^{60}$ Id. (statement of Mr. Bilirakis of Florida).

${ }^{61}$ Id. (statement of Mr. Bilirakis of Florida).

${ }^{62}$ Cf. id. ("[PSQIA] strikes an appropriate balance between encouraging the reporting of valuable information, which will be used to save lives, and safeguarding the ability of individuals to access necessary information to seek judicial redress when appropriate.") (statement of Mr. Bilirakis of Florida).

63 151 CONG. REC. S8741, S8741 (2005) (statement of Mr. Enzi of Wyoming). 
PSQIA will not protect such information. ${ }^{64}$ Rather, the PSQIA merely "create[d] a new zone of protection to assure that the assembly, deliberation, analysis, and reporting by providers to patient safety organizations or what we are calling 'Patient Safety Work Product' will be treated as confidential and will be legally privileged." 65 The privilege created by the PSQIA is important because, it is extremely unlikely that, without this protection, providers would partake in voluntarily reporting their own medical errors. ${ }^{66}$

\section{E. The Main "Players" of the PSQIA}

The persons and entities that are affected by the PSQIA consist of patients, health care providers, and PSOs. While the PSQIA does not provide a specific definition for the word "patient," for the purposes of this note, "patient" will be defined as a person who has obtained medical attention from a health care provider. The PSQIA does, however, provide explicit definitions for the other two types of players it affects. ${ }^{67}$

According to the PSQIA, a "provider" is "an individual or entity licensed or otherwise authorized under state law to provide health care services."68 These entities include institutional providers such as hospitals and nursing homes, as well as individual providers such as physicians and nurses. ${ }^{69}$ The providers, both institutional and individual, are the players of the PSQIA that will utilize the voluntary reporting mechanism which is made operational by PSOs.

Further, the PSQIA defines a "patient safety organization" (PSO) as "a private or public entity or component thereof that is listed by the Secretary pursuant to [the PSQIA]." ${ }^{, 70}$ Currently, the regulations pertaining to the PSQIA have not yet been promulgated; however, the PSQIA sets forth very specific criteria for PSO certification, ${ }^{71}$ with which the future regulations will comply.

In order to be a certified PSO, the PSQIA requires, among several criteria, ${ }^{72}$ that "[ $\left.\mathrm{t}\right]$ he mission and primary activity of the entity are to conduct activities that are to improve patient safety and the quality of health care delivery."73 Additionally, the PSO seeking certification will be expected to engage in such activities as the "utilization of patient safety work product for the purpose of

${ }^{64}$ Id

${ }^{65}$ Id. (statement of Mr. Enzi of Wyoming).

66 Id.

${ }^{67}$ Patient Safety and Quality Improvement Act of 2005, Pub. L. No. 109-41, $\$ 921,119$

Stat. 424, 425 (codified as amended in scattered sections of 42 U.S.C.).

${ }^{68}$ Id. $\S 921(8)(\mathrm{A})$.

${ }^{69}$ Id. $\S 921(8)(\mathrm{A})(\mathrm{i})-(\mathrm{ii})$.

70 Id. $\S 921(4)$.

71 Id. § 924(a)-(b).

${ }^{72}$ Id. § 924(b)(1)(A)-(G).

${ }^{73}$ Id. $\S 924(\mathrm{~b})(1)(\mathrm{A})$. 
providing direct feedback and assistance to providers to effectively minimize patient risk,"74 and the collection of "patient safety work product from providers in a standardized manner that permits valid comparisons of similar cases among similar providers."75 Additionally, the organization cannot be an insurance provider; nor can it have any conflicts of interest in carrying out its activities as a patient safety organization. ${ }^{76}$ Finally, if the PSO is related to another entity that provides services apart from those provided by a PSO, the patient safety section of the entity must remain separate from the rest of the entity and must not allow any of the information it obtains in its capacity as a PSO to be circulated to the other branches of the entity. ${ }^{77}$

\section{F. The Reporting System}

The voluntary reporting system created by the PSQIA is intended to create an incentive for health care providers to report medical errors to the PSO with which the providers contract. In theory, the voluntary nature of the reporting system installs safeguards to ensure providers will not be harmed by litigation as a result of reporting errors.

Only certain data will gain the privilege that is established by the PSQIA. This data is termed "patient safety work product" and defined by the PSQIA to include:

[A]ny data, reports, records, memoranda, analyses (such as root cause analyses), or written or oral statements(i)which-(I) are assembled or developed by a provider for reporting to a patient safety organization and are reported to a patient safety organization; or (II) are developed by a patient safety organization for the conduct of patient safety activities; and which could result in improved patient safety, health care quality, or health care outcomes; or (ii) identify or constitute the deliberations or analysis of, or identify the fact of reporting pursuant to, a patient safety evaluation system. ${ }^{78}$

The data described above does not include "a patient's medical record, billing and discharge information, or any other original patient or provider record." In addition, it does not include "information that is collected, maintained, or developed separately, or exists separately, from a patient safety

${ }^{74}$ Id. $\S 924(\mathrm{~b})(1)(\mathrm{G})$.

75 Id. § 924(b)(1)(F).

${ }^{76}$ Id. $\S 924(\mathrm{~b})(2)(\mathrm{C})$

77 Id. $\S 924(\mathrm{~b})(2)(\mathrm{A})-(\mathrm{C})$.

78 Id. $\S 921(7)(\mathrm{A})(\mathrm{i})-(\mathrm{ii})$.

79 Id. § 921(7)(B)(i). 
evaluation system." of being reported to a PSO will be deemed patient safety work product. ${ }^{81}$

\section{Privilege Provision}

The PSQIA includes a provision that grants an evidentiary privilege to patient safety work product. ${ }^{82}$ This privilege does not apply, however, to patient safety work product "merely by reason of its inclusion in reported patient safety data." ${ }^{\circ 3}$ Only the data that qualifies as patient safety work product under the PSQIA will gain the privilege. ${ }^{84}$

Patient safety work product enjoys a generous evidentiary privilege making it exempt from disclosure in the following proceedings and situations:

Federal, State, or local civil, criminal, or administrative subpoena or order, including in a Federal, State, or local civil or administrative disciplinary proceeding against a provider; . . . discovery in connection with a Federal, State, or local civil, criminal, or administrative proceeding, including in a Federal, State, or local civil or administrative disciplinary proceeding against a provider; ... disclosure pursuant to section 552 of title 5 , United States Code (commonly known as the Freedom of Information Act) or any other similar Federal, State, or local law; .... ${ }^{85}$

Furthermore, patient safety work product will not be admissible evidence in any type of state or federal proceeding, whether it is civil, criminal, administrative rulemaking or administrative adjudication. ${ }^{86}$ Such information is also protected from use in professional disciplinary proceedings held by disciplinary bodies formed under State law. ${ }^{87}$

While patient safety work product does enjoy an evidentiary privilege, such a privilege does not come without limitation. Certain rights must be pre-

${ }^{80}$ Id. $\S 921(7)(\mathrm{B})(\mathrm{ii})$.

81 Id. ("Such separate information or a copy thereof reported to a patient safety organization shall not by reason of its reporting be considered patient safety work product.").

${ }^{82}$ Id. $\S 922(\mathrm{a})$.

${ }^{83}$ H.R. REP. No. 108-31, at 14 (2003).

${ }^{84}$ Id.; Patient Safety and Quality Improvement Act $\$ 922(a)$. The privilege provides that patient safety work product "[will] not be subject to: (1) a civil or administrative subpoena; (2) discovery in connection with a civil or administrative proceeding; (3) disclosure pursuant to a Freedom of Information Act request; or (4) admission as evidence or disclosure in any civil or administrative proceeding." H.R. REP. No. 108-31, at 14.

85 Patient Safety and Quality Improvement Act $\$$ 922(a)(1)-(3).

${ }^{86} I d . \S 922(\mathrm{a})(4)$.

87 Id. $\S 922(\mathrm{a})(5)$. 
served in the course of providing a privilege to such data, and as a result Congress crafted specific exceptions to the granted privilege.

For example, after the court has made an "in camera determination that such patient safety work product contains evidence of a criminal act and that such patient safety work product is material to the proceeding and not reasonably available from any other source ..."88 the data will be excepted from the privilege and will be admissible in court. ${ }^{89}$ In addition, other obvious exceptions to the rule against disclosure exist, including situations where the health care provider identified in patient safety work product authorizes the disclosure. $^{90}$

\section{Confidentiality Provision}

The PSQIA's confidentiality provision states that patient safety work product "shall be confidential and shall not be disclosed," notwithstanding other federal, state, or local law. ${ }^{92}$ In addition to the exceptions that apply to both the privilege and confidentiality provisions, the PSQIA further exempts the confidentiality provision from certain disclosures. ${ }^{93}$ Specifically, the confidentiality provision does not prohibit information sharing when such information is used for the purpose of carrying out activities relating to patient safety, or if the information is non-identifiable under the PSQIA. ${ }^{94}$ The PSQIA also provides that when the disclosure of information would be allowed under the Health Insurance Portability and Accountability Act ("HIPAA"), such patient safety work product is not protected by the confidentiality provision. ${ }^{95}$ The confidentiality provision also will not protect patient safety work product when it is being disclosed by the health care provider to certain entities such as the Food and Drug Administration ("FDA") and accrediting bodies that accredit the provider. $^{96}$

\section{WILl THE PATIENT SAFETY AND QUALITY IMPROVEMENT ACT OF 2005 ACHIEVE THE RESULTS CONGRESS INTENDED?}

Lawmakers seem to be hopeful that the enactment of the PSQIA will result in a reduction in medical errors. Lawmakers may have failed to account, however, for the fact that the reporting of the medical errors is still left up to

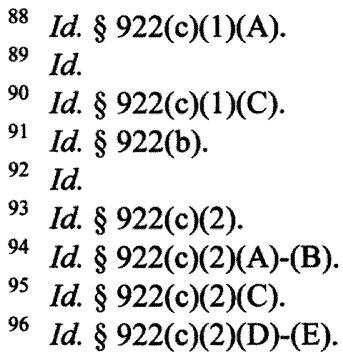


those who commit them. While peer review committees were established with the best intentions in mind, the attitudes that providers hold of them no longer seem to reflect those beneficent purposes. Instead, two new perceptions held by health care providers of peer review committees have emerged: that peer review is underused and misused. ${ }^{97}$

\section{A. Anticipated Underutilization of PSOs by Providers}

The purpose of the privilege and confidentiality provisions of the PSQIA is to ensure those providers who report such errors that their disclosure will be studied and analyzed by professionals in order to find ways to reduce future errors. There is reason to believe, however, that even Congress's best intentions may not be enough to deter providers from reporting such errors for fear of losing their jobs or suffering damage to their reputation as a result of the disclosure. For instance, one concern that providers share is if they admit to the errors they have committed, they risk being regarded as incompetent by fellow providers. ${ }^{98}$ Additionally, "[p]hysicians and facility employees, primarily nurses, are also concerned about job security and the use of reports in disciplinary and adverse employment actions." physicians and other health care providers, the frequency of utilization of the reporting systems to be developed under the PSQIA is questionable at best.

Additionally, a natural phenomenon that is likely to hinder the rate of voluntarily reported medical errors is the traditional assumption that health care performance is expected to be largely flawless and purely beneficial. Consequently, when errors occur, the natural tendency does not seem to be for the provider who committed the error to report it, and yet such reporting is theoretically required in order to prevent future errors. ${ }^{100}$

Additionally, many argue that peer review is underutilized as a result of physicians' reluctance to criticize their colleagues. ${ }^{101}$

When providers discuss their reluctance to report the details of error events, they cite fear of retribution, ethical dilemmas, and economic pressures. Even providers who understand complex system errors and the importance of

97 See Weiss, supra note 12 , at $48,51$.

98 Maxine M. Harrington, Revisiting Medical Error: Five Years After the IOM Report, Have Reporting Systems Made a Measurable Difference?, 15 HeAlth MATRIX 329, 352-53 (2005).

99 Id. at 354 \& n.160 (citing Thomas R. McLean, The Implications of Patient Safety Research \& Risk Managed Care, 26 S. ILL. U. L.J. 227, 235-36 (2002)).

100 See Patricia R. EBright \& Kathrin RAPALA, CTR. FOR URBAN POL'Y \& ENV'T, A CHALlENGe For INDIANA: MEDICAL ERROR REPORTING SySTEM CoULd BOOST PATIENT SAFETY 4 (2005).

${ }^{101}$ E.g., Weiss, supra note 12 , at $48,51$. 
learning from them hesitate to report problems because they know that the public often does not understand the complexity of the situation, and this lack of understanding may have legal implications for the provider. ${ }^{102}$

Alice G. Gosfield, an attorney from Philadelphia, says that "[p]hysicians judging their colleagues are very concerned about the potential impact of peer review, so they'll go through all kinds of contortions to avoid taking action. So, when physicians or administrators move forward, it's usually justifiable.",103

In addition to the basic assumption that providers will not voluntarily report their medical errors, medical reporting system statistics also show providers' reluctance to report adverse events. The most prominent example can be found through the recent use of The Joint Commission Sentinel Event Policy. ${ }^{104}$ The documented compliance with this Policy serves as a useful measurement for the purposes of this Note because "sentinel events" are unexpected negative occurrences, such as medication errors, wrong-site surgeries, delay in treatment, and other negligence-related events, ${ }^{105}$ which logically suggest that they are likely the result of medical errors. The Policy requires The Joint Commissionaccredited entities to establish within their own policies a definition of "sentinel event" that must be consistent with The Joint Commission's general definition. ${ }^{106}$ Based on the accredited entity's definition of "sentinel event," if such an event occurs the entity must follow certain guidelines. ${ }^{107}$ One action that the entity is encouraged to take is reporting the occurrence of the sentinel event to The Joint Commission. ${ }^{108}$ Similar to the PSQIA's voluntary scheme, reporting of sentinel events is not required; however, if The Joint Commission learns of the event, the accredited entity is expected to submit to the root cause analysis and action plan that followed the occurrence. ${ }^{109}$ The Joint Commission will then decide if the accredited entity's handling of the sentinel event has met its

102 EBRIGHT \& RAPALA, supra note 100.

103 Weiss, supra note 12 , at 51.

104 THE JOINT COMM'N, supra note 11.

105 The JoInt Comm'N, Sentinel Event Statistics: As of June 30, 2006 (2006), http://www.jointcommission.org/NR/rdonlyres/74540565-4D0F-4992-863E8F9E949E6B56/0/se_stats_6_30_06.pdf.

106 THE JOINT COMM'N, supra note 11, at 1 ("A sentinel event is an unexpected occurrence involving death or serious physical or psychological injury, or the risk thereof. Serious injury specifically includes loss of limb or function. The phrase, 'or the risk thereof' includes any process variation for which a recurrence would carry a significant chance of a serious adverse outcome.").

107 Id. For example, the entity must engage in a root cause analysis of the event which includes following up with the persons involved to make sure that the process is effective in reducing the likelihood of the same type of event occurring in the future. Id.

108 Id.

109 Id. 
standards. ${ }^{110}$ In conjunction with its Sentinel Event Policy, The Joint Commission has published statistics relating to sentinel events that shed light on the rate at which providers report their own medical errors.

From January of 1995 through December of 2004, nearly 3,000 sentinel events throughout the United States were reviewed by The Joint Commission, meaning that The Joint Commission was actually notified of the sentinel event. ${ }^{111}$ Of these 3,000 events, over half were self-reported. Thirty-seven percent of the sentinel events that The Joint Commission reviewed, however, came from the media or other sources, rather than from the accredited entity in which the sentinel event occurred. ${ }^{112}$ While it is encouraging to see that sixty-three percent of sentinel events were self-reported, the lagging thirty-seven percent is a good indicator that the PSQIA is not likely to enjoy error reporting participation from all providers.

\section{B. Likely Development of Bad Faith or Sham Peer Review}

\section{A Look at State Peer Review Protection Statutes That Have Been Used in Good Faith}

A familiar trend among health care providers in the U.S. today is the implementation and frequent utilization of peer review committees that are governed by state peer review protection statutes. Many states have in place some form of a peer review protection statute that allows health care providers to report amongst themselves errors and adverse events that take place within their institutions. ${ }^{113}$ A few legitimate and "good faith" practical uses have come about as a result of peer review protection, as well as a few illegitimate practices.

Perhaps the most ideal notion behind peer review protection statutes is to allow a health care institution to learn from its mistakes and as a result make amends with affected parties, which may in turn curb litigation. For example, if a doctor prescribes a drug to a patient in a slightly higher than recommended yet still tolerable amount, the doctor should have the opportunity to report the error to the hospital's peer review committee. The purpose of reporting would be to allow the peer review committee to investigate the situation, attempt to settle grievances with the patient, and provide education to other health care providers in order to reduce the occurrence of such mistakes in the future. Therefore, the doctor should be able to report the error without fear that this information will be used by the hospital or the patient against him.

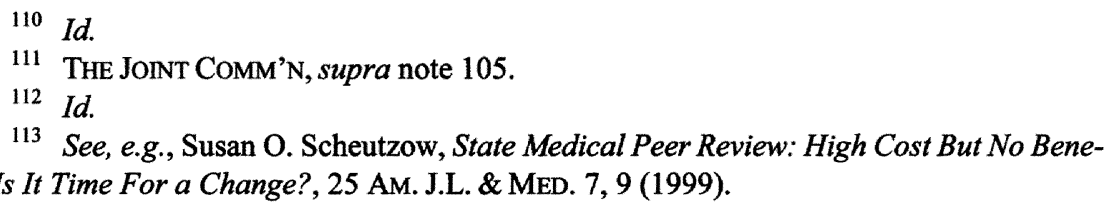


Another reason behind peer review protection is the notion that physicians are most familiar with the appropriate standard of care, and they are most capable of deciding whether one of their colleagues has breached that standard. If, after an appropriate and fairly-conducted peer review process, it is decided that a physician has in fact breached the pertinent standard of care, then it may be proper for the peer review committee to recommend or implement disciplinary action against the physician. However, it is not always the case that peer review processes are conducted fairly, nor that disciplinary action is always warranted or deserved.

\section{Sham Uses of Peer Review Statutes and Policies}

While state peer review protection statutes have created positive results in terms of error reduction and information sharing, it has also had one particularly unfortunate side effect. Rather than using peer review committees for analyzing and attempting to correct adverse events or to discipline health care providers who deserve to be disciplined, a current trend among hospitals is to use the committees as a way to weed out competition.

Consider, for example, the case of Lawrence Poliner, a cardiologist from Dallas, Texas. ${ }^{114}$ Like many other peer review committees, the committee at the hospital for which he worked has the authority and duty to consider the physician's mistakes and decide which disciplinary action is most appropriate. ${ }^{115}$ Three of his colleagues were found to have "trumped up charges of substandard care against him to eliminate him as a competitor."116 Upon this finding, the jury awarded Dr. Poliner \$366 million in damages. ${ }^{117}$

Another example of a "bad faith" peer review involved a general surgeon named Timothy Patrick. ${ }^{118}$ Dr. Patrick sued those who initiated a peer review proceeding against him, alleging that the review was "designed to drive him out of business so competitors could co-opt his practice." ${ }^{119}$ It was the jury's award to Dr. Patrick of $\$ 650,000$ (which the court trebled) that prompted the push for national legislation to provide "liability protection to physicians who file complaints against colleagues and serve on peer review panels."120

Many physicians are beginning to take the view that "[n]ot only is the peer review process corrupt, it's ineffective." 121 "Rather than being used to weed out bad doctors, peer review as it exists today is used primarily as a weapon

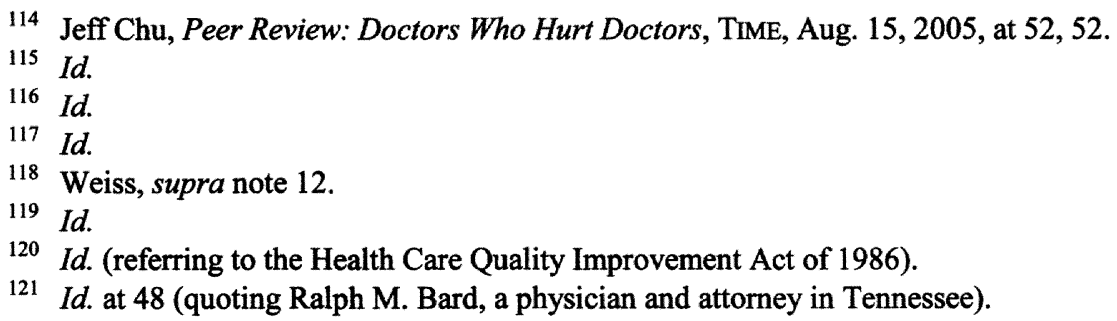


against young, vulnerable practitioners." ${ }^{\text {"122 }}$ In another context, Mary H. Johnson, a pediatrician who lost her job subsequent to making a report to a peer review committee regarding a colleague's mismanagement of a newborn's care, stated, "[t]he abuse of peer review for economic reasons or to perpetuate a cover-up is medicine's dirtiest little secret . ..."123

Consider also the case of Dr. Thomas Wieters, a general surgeon from Charleston, South Carolina. ${ }^{124}$ Dr. Wieters made a call to the hospital's CEO after finding that one of his elderly patients, who was scheduled for surgery to manage his abdominal aortic aneurysm, had been in the hospital for eleven hours without having any blood work or a cardiogram done. ${ }^{125}$ After the CEO reached the unit to speak to Dr. Wieters, Dr. Wieters politely asked him why his aneurysm patient had been waiting for more than eleven hours with no blood work done and without having received his cardiac medicines. ${ }^{126}$ Two weeks after this incident, "Dr. Wieters received a certified letter charging him with "disruptive behavior.",127

A general surgery committee that was formed to review the charges against Dr. Wieters found that they "did not merit disciplinary action, as Dr. Wieters' admonishments were always directed at failures to provide standard of care." 28 Nonetheless, an executive medical committee disagreed, and required Dr. Wieters to undergo psychiatric evaluation and placed him on a one-year probation. ${ }^{129}$ While his peer review hearings were ongoing, "Dr. Wieters continued to write incident reports detailing examples of negligent care." Dr. Wieters defended himself, saying, "“[t]hese were my patients, and I would not look the other way' ....,"130

Soon thereafter Dr. Wieters was put on summary suspension, a disciplinary action supposedly, "reserved for instances when a physician poses an imminent danger to a patient or patients." the immediate cessation of income in the face of significant legal expenses for self-defense[,]" caused the hospital administrators to notify the National Practitioner Data Bank concerning Dr. Wieters' status. ${ }^{132}$ This data bank represents a list of physicians who have been "blacklisted for malpractice, incompetence

122 Id

123 Id.

124 William M. Johnston, Shammed I Am, in Peer Review: Due Process Does Not Apply for Physicians Facing Sham Peer Review, GEN. SURGERY NEWS, June 2004, at 1, available at http://www.semmelweis.org/Acrobat/article_sham $\% 20 \mathrm{i} \% 20 \mathrm{am}$.pdf.
125 Id.
126 Id.
127 Id. at 2
128 Id.
$129 \mathrm{Id}$.
130 Id.
131 Id
132 Id. 
and dependency problems as a threat to the safety of patients."133 The HCQIA, ${ }^{134}$ from which the National Practitioner Data Bank was born, has been said to be "'a club, a sword that allows hospitals to do whatever they want to do: lie, cheat, embellish, ameliorate, alter records, [and] commit fraud . ...",135 Ironically, the HCQIA, which was intended to achieve many of the same objectives as the PSQIA, has led to illegitimate disciplinary action against physicians who have done nothing but try to improve the safety and care of their patients.

The HCQIA was designed and enacted with the intention of allowing open discussion on the matters of medical errors and adverse events, which is the very basis upon which the PSQIA was formed. ${ }^{136}$ If the results of the HCQIA and medical peer review protection in general are signs of things to come under the PSQIA, it can reasonably be expected that physicians who practice medicine with the habit of reporting substandard medical care and correcting medical errors will be forced from their positions on medical staffs at an even higher rate than what is seen today.

In response to this argument, proponents of the PSQIA will cite the provision that prohibits the use of information reported to the PSOs in adverse disciplinary actions. ${ }^{137}$ Proponents may even cite this section as the cure for the disease of sham peer review; however, the major flaw in such an idealistic argument is the fact that there is always another way to eliminate the whistleblowing employee.

In fact, the "bad faith" use of peer review committees has become so widespread that an entire organization, the Semmelweis Society, has been formed to "help physicians ensnared in what ... [its vice president] calls 'sham peer review." "138 The Semmelweis Society is dedicated to helping victimized health care providers, whose plight seems to be a driving factor behind this first group's opinion of peer review. ${ }^{139}$

\section{a. The Semmelweis Society and protecting physicians from} sham peer review

Dr. Semmelweis, after whom the Semmelweis Society is named, ${ }^{140}$ was a

133 Id.

134 Id. See generally Health Care Quality Improvement Act of 1986, Pub. L. No. 99-660,

100 Stat. 3784 (codified as amended in scattered sections of 42 U.S.C.).

135 Johnston, supra note 124, at 2.

136 Id.

137 Patient Safety and Quality Improvement Act of 2005, Pub. L. No. 109-41, § 922(a),

119 Stat. 424, 427 (codified as amended in scattered sections of 42 U.S.C.).

138 Weiss, supra note 12, at 48 (referring to the Semmelweis Society). See generally Semmelweis Soc'y Int'l, supra note 14.

139 See generally Semmelweis Soc'y Int'1, About

Semmelweis, http://www.semmelweis.org /about.htm (last visited Feb. 19, 2007).

140 Johnston, supra note 124 , at 3. 
"19th-century Hungarian-born physician who crusaded for sterile conditions at the Vienna General Hospital." ${ }^{141}$ Of the two obstetric clinics in the hospital, the one in which Dr. Semmelweis worked, had a thirteen percent maternal and infant mortality rate, while the other clinic's mortality rate was only two percent. $^{142}$ Like many of the other physicians who worked in his clinic, Dr. Semmelweis frequently went back and forth between working with cadavers and delivering babies in the obstetrics clinic. ${ }^{143}$ Upon realizing that the mortality rate in his clinic was due to physicians carrying infection on their hands from the autopsy room to women in labor, Dr. Semmelweis pushed for the regular "practice of hand washing with a solution of chlorinated lime between autopsy work and the examination of patients."144

Soon after the mortality rate in Dr. Semmelweis' clinic dropped to two percent, his superior, who had always objected to Dr. Semmelweis' demand for sterile conditions, refused to reappoint him to the faculty. ${ }^{145}$ Hence, the guiding principle of the Semmelweis Society, "peer review should always be done 'with clean hands.",146

Medical peer review committees are currently being used in some cases to weed out health care providers who make a habit of whistle blowing. When new physicians are told, first, to do no harm, surely they do not expect to be bullied into doing exactly the opposite. As Dr. Semmelweis' case has shown, staying in business as a doctor may require dismissing one's better instincts and allowing medical errors to be forgotten immediately after they occur.

Consider again the example of Dr. Wieters who was eventually fired for "disruptive behavior." "147 In actuality, Dr. Wieters had merely been writing incident reports that reflected his colleagues' substandard care. ${ }^{148}$ It can hardly be doubted that, in the face of providers who insist on complying with the objectives of the PSQIA, hospital administrators will act in the same malevolent fashion as those who held Dr. Wieters' fate in their hands. Little imagination, and even less motivation, is required to craft a justifiable reason for excusing a health care provider who, through his or her reporting conduct, threatens to tarnish the reputation of the organization for which he or she works.

Members of Congress are hopeful that those who believe peer review is being misused will find comfort in the PSQIA's provisions that protect the information used in medical error reports from being used as grounds for adverse employment actions. ${ }^{149}$ Although Congress clearly intends for such protection

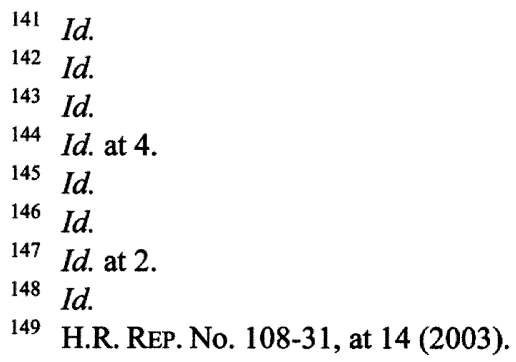


from adverse employment actions to be effective in practice, it is highly likely that it will perpetuate adverse employment action, instead of diminish it. After all, it was not until after the Health Care Quality Improvement Act of 1986 that the medical peer review process took its downhill turn toward abuse and misuse. $^{150}$

\section{CONCLUSION}

It has been said that "no good deed goes unpunished."151 Perhaps physician-victims of sham peer review can identify with this expression. Arguably, this is the very type of peer review that will be provoked by a national movement toward voluntarily reporting medical errors through the PSQIA.

The success of the PSQIA relies on those health care providers who will voluntarily come forward with information of medical errors that they have committed or that they have witnessed. Only then will the PSOs, certified under the PSQIA, have enough information to analyze and distribute meaningful data that will educate health care providers about the dangerous trends that result in such errors. Unfortunately, these same providers, the ones who have been willing to voluntarily report the grave medical errors committed by themselves and their colleagues, are the providers who have been persecuted and driven off of their respective medical staffs for doing just that. This occurrence is likely due to the fear held by medical staffs and hospitals that reported information will get into the wrong hands and will be used to the detriment of the provider or the health care organization.

From the general public's standpoint, the provider who will strive for safer techniques, who will report the substandard care being provided by her colleagues, and who strives to rectify the wrongs that she herself has caused, is held in very high esteem. For she is the kind of provider we would like to see more of in our hospitals; she is the kind of provider whose good intentions will lead to the success of the PSQIA. From the hospital's point of view, however, the very same doctor is seen in a dramatically different light. To the hospital system, which is aiming to maintain its good reputation among the public, she is the kind of provider who threatens to raise the cost of care by demanding those more costly, yet safer techniques, and who threatens to draw adverse attention to the hospital.

With the practice of sham peer review already at work in the U.S. today, the forecast for the utilization of the process created by the PSQIA is rather $\mathrm{dim}$. The nasty side-effect of legislation that encourages health care providers

150 Johnston, supra note 124.

151 See, e.g., Wikipedia, Clare Boothe Luce, http://en.wikipedia.org/wiki/Clare Boothe_Luce (last visited Feb. 19, 2007) (stating that Luce, a twentieth-century editor, social activist, playwright, journalist, diplomat, and politician, was known for this oft-quoted aphorism). 
to report their errors is likely to be widespread illegitimate disciplinary action taken against the very physicians and nurses upon which the success of the PSQIA relies. Because this very result has already been seen in cases as early as Dr. Semmelweis' and as recent as Dr. Wieters', it is highly unlikely that health care providers will report medical errors at a high enough rate to accumulate data that will lead to a truly meaningful analysis and reduction in medical errors. Thus, the grim conclusion of this Note: the PSQIA may initially spur an increased rate of medical error reporting, which, it is feared, will likely spawn an increased rate of sham peer review processes and in turn will be followed by an extreme decrease in the rate of error reporting. All in all, it is highly likely that the PSQIA will have an effect contrary to that which Congress intended. 